\title{
Source apportionment of elevated wintertime PAHs by compound-specific radiocarbon analysis
}

\author{
R. J. Sheesley, M. Kruså, P. Krecl, C. Johansson, and Ö. Gustafsson \\ Department of Applied Environmental Science (ITM), Stockholm University, 10691 Stockholm, Sweden
}

Received: 1 September 2008 - Published in Atmos. Chem. Phys. Discuss.: 12 December 2008

Revised: 15 May 2009 - Accepted: 15 May 2009 - Published: 25 May 2009

\begin{abstract}
Natural abundance radiocarbon analysis facilitates distinct source apportionment between contemporary biomass/biofuel $\left({ }^{14} \mathrm{C}\right.$ "alive") versus fossil fuel ( ${ }^{14} \mathrm{C}$ "dead") combustion. Here, the first compound-specific radiocarbon analysis (CSRA) of atmospheric polycyclic aromatic hydrocarbons (PAHs) was demonstrated for a set of samples collected in Lycksele, Sweden a small town with frequent episodes of severe atmospheric pollution in the winter. Renewed interest in using residential wood combustion (RWC) means that this type of seasonal pollution is of increasing concern in many areas. Five individual/paired PAH isolates from three pooled fortnight-long filter collections were analyzed by CSRA: phenanthrene, fluoranthene, pyrene, benzo[b+k]fluoranthene and indeno[cd]pyrene plus benzo[ghi]perylene; phenanthrene was the only compound also analyzed in the gas phase. The measured $\Delta^{14} \mathrm{C}$ for PAHs spanned from $-138.3 \%$ o to $58.0 \%$ o. A simple isotopic mass balance model was applied to estimate the fraction biomass $\left(f_{\text {biomass }}\right)$ contribution, which was constrained to $71-87 \%$ for the individual PAHs. Indeno[cd]pyrene plus benzo[ghi]perylene had an $f_{\text {biomass }}$ of $71 \%$, while fluoranthene and phenanthrene (gas phase) had the highest biomass contribution at $87 \%$. The total organic carbon (TOC, defined as carbon remaining after removal of inorganic carbon) $f_{\text {biomass }}$ was estimated to be $77 \%$, which falls within the range for PAHs. This CSRA data of atmospheric PAHs established that RWC is the dominating source of atmospheric PAHs to this region of the boreal zone with some variations among RWC contributions to specific PAHs.
\end{abstract}

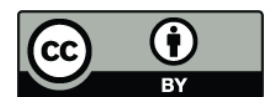

Correspondence to: Ö. Gustafsson (orjan.gustafsson@itm.su.se)

\section{Introduction}

Polycyclic aromatic hydrocarbons (PAHs) are ubiquitous in the atmosphere and are primarily emitted by anthropogenic sources including fossil fuel and biomass combustion. Some PAHs are very well known carcinogens and several studies indicate a negative impact of atmospheric PAHs on human and ecological health (Busby et al., 1997; Hedberg and Johansson, 2006; Choi et al., 2006; Sauvain et al., 2003; Schwarze et al., 2007). To abate the adverse health effects caused by these pollutants, source apportionment studies are needed to inform effective strategies and air quality regulations to control PAH emissions.

Apportioning PAHs to a specific combustion source can be difficult (Hays et al., 2003; Schauer et al., 2001, 2002; McDonald et al., 2003) and inventories and reviews have been written to determine sources and regulatory tactics (Breivik et al., 2006; Ravindra et al., 2008). Differences due to biomass or fossil fuel type and to combustion conditions determine PAH ratios (Benner et al., 1995; Yan et al., 2005; Yunker et al., 2002), and can confound efforts to apportion PAHs in an environmental sample; this also limits their utility as generic biomass or fossil fuel combustion tracers as very location- and source-specific profiles are needed for accurate apportionment (Mandalakis et al., 2004a; Lima et al., 2005). Factor-analysis-based source apportionment, such as principal component analysis and positive matrix factorization (PMF), has been used to attempt to define source contributions to PAHs with mixed success (Larsen and Baker, 2003). The advantage to methods like PMF is that it requires no source profile input. However, the goal is often to define the factors as specific sources, which does require knowledge of PAH distribution in local source emissions. PMF also requires a large dataset to be effective, which is not always feasible. There is interest both in ascertaining the sources of PAHs and in accurately using PAHs as source tracers

Published by Copernicus Publications on behalf of the European Geosciences Union. 
in the atmosphere to quantify the contribution of emission sources to total atmospheric organic carbon (OC). Specific PAHs may be more valuable as molecular markers than others in source apportionment models for OC when used in conjunction with more unique tracers such as hopanes and levoglucosan (Chow et al., 2007; Jaeckels et al., 2007; Lough and Schauer, 2007). However, more investigation into the sources of individual atmospheric PAHs is warranted to inform current source apportionment techniques.

Natural abundance radiocarbon analysis enables determination of the contribution of fossil and non-fossil sources to carbonaceous compounds. Basically, the ${ }^{14} \mathrm{C}$ in atmospheric $\mathrm{CO}_{2}$ dictates the ${ }^{14} \mathrm{C}$ in fresh carbon and this then decays with a half-life of 5730 years. Hence, radiocarbon is ideal to distinguish between fossil fuel (void of ${ }^{14} \mathrm{C}$ ) and biomass/biofuel (contemporary ${ }^{14} \mathrm{C}$ ) combustion sources. However, the large sample masses traditionally required for radiocarbon analysis has largely limited its application in atmospheric particulate matter to characterizing total or bulk organic carbon (Hildemann et al., 1994; Jordan et al., 2006; Szidat et al., 2004a; Bench et al., 2007). For bulk carbon, contemporary sources can include both biogenic emission and biomass combustion sources, so these results can only be used to define contribution of fossil fuel combustion sources including motor vehicles and power generation. Advances in molecular-level radiocarbon analysis (Eglinton et al., 1996) have allowed compound class-specific radiocarbon analysis (CCSRA) of atmospheric PAHs (Mandalakis et al., 2005; Zencak et al., 2007b; Kumata et al., 2006). These studies have revealed geographic differences in fossil vs. modern biomass sources of PAH across Europe and in Japan. The study from Japan is compelling as it indicates the importance of isolating individual PAHs for compound-specific radiocarbon analysis (CSRA) by revealing differences in the contribution from biomass burning between pooled low versus high molecular weight PAHs (Kumata et al., 2006). These results combined with emission source profiles suggest that source contributions would not be uniform for all PAHs.

To further consider the source apportionment of individual atmospheric PAHs, a residential area in a northern Swedish town was chosen for a winter sampling campaign. Lycksele, Sweden has been the site of previous atmospheric studies due to the high levels of ambient particulate matter and PAHs (Johansson et al., 2004; Hedberg and Johansson, 2006) and the high percentage of households using biofuels for space heating during wintertime (Hedberg and Johansson, 2006; Krecl et al., 2007); this is a typical situation for small towns in the northern boreal zone. The contribution of elemental carbon (EC) and $\mathrm{OC}$ to the total $\mathrm{PM}_{10}$ mass concentration was on average $11 \%$ and $35 \%$, respectively, in winter 2006 (Krecl et al., 2008a). High correlations $(R>0.75)$ were found among $\mathrm{PM}_{1}, \mathrm{PM}_{10}$, light absorbing carbon mass concentrations and particle number concentrations for Lycksele, which were associated with known traffic emission and biomass burning particle size distributions (Krecl et al., 2008b). A large day- to-day and hour-to-hour variability in aerosol concentrations was also observed with evening aerosol concentrations significantly higher on weekends than on weekdays, presumably associated with residential wood combustion (RWC) emissions. Local traffic emissions were identified based upon their similar contribution every day and characteristic peak in the morning and in the evening (Krecl et al., 2008a). RWC and traffic emissions were thus identified as the two major local sources using several techniques, with long-range transport contributing to a lesser degree. In the current study, the relative impact of the RWC and traffic emissions is quantified by performing radiocarbon analysis of total carbon and CSRA of PAHs on atmospheric samples collected in Lycksele during the winter of 2006.

\section{Experimental section}

\subsection{Sample collection and treatment}

Sampling was carried out in a residential neighborhood (Forsdala) in the town of Lycksele $\left(64.55^{\circ} \mathrm{N}, 18.72^{\circ} \mathrm{E}, 8600\right.$ inhabitants) over a 6-week period from 23 January to 8 March 2006. The samples were composited to achieve a representative winter sample for Lycksele. Details on the sampling site and meteorological conditions can be found elsewhere (Krecl et al., 2007, 2008a). Two custom-built highvolume samplers were employed (Broman et al., 1991), each one consisting of an inverted filter holder which collected total suspended particle matter (TSP) on borosilicate glass fiber filters (GFF, 293 mm diameter, Millipore, USA). Downstream of the GFF filters were two sequential polyurethane foam (PUF) traps for collecting volatile compounds. Filter changes were made on a 2-week schedule while PUF were replaced on a 1-week schedule to limit potential breakthrough. During the initial two weeks (23 January-6 February), the sampling was conducted with both GFF and PUFs; sampler A had an average flow rate of $24 \mathrm{~m}^{3} \mathrm{~h}^{-1}$ and sampler $B$ had an average flow rate of $20 \mathrm{~m}^{3} \mathrm{~h}^{-1}$. For the final four weeks of the campaign (6 February-8 March), the sampling was performed only in the particle phase with an average flow rate of $\sim 35 \mathrm{~m}^{3} \mathrm{~h}^{-1}$ for both samplers. In total, three sets of two-week filter samples and two sets of oneweek PUF samples were collected. Additionally, one filter blank and two PUF blanks were transported to and from the measurement site together with the other filters and PUFs and were exposed outdoors in the sampling equipment for $30 \mathrm{~s}$. Long sampling periods may introduce both positive and negative sampling artifacts (Ravindra et al., 2008), but the cold temperatures in Lycksele were expected to effectively limit partitioning and reactions of PAHs and organic carbon and subsequent artifacts. Results from PUF and filter comparisons indicate that only phenanthrene had significant concentrations in the gaseous phase. Isotope ratios are an intensive property, so although concentrations (an extensive 
Table 1. Carbon isotope results for bulk TOC and individual PAHs in Lycksele during winter campaign 2006.

\begin{tabular}{lllrrc}
\hline Dates & Compound $^{\mathrm{a}}$ & Media & $\delta^{13} \mathrm{C}^{\mathrm{b}}(\% \circ)$ & $\Delta^{14} \mathrm{C}(\%$ o & \multicolumn{1}{c}{$f_{M}$} \\
\hline 2-week samples & & & & & \\
23 Jan-6 Feb & TOC & GFF & -26.68 & -23.7 & $0.983 \pm 0.010$ \\
6 Feb-20 Feb & TOC & GFF & -26.41 & -75.1 & $0.931 \pm 0.008$ \\
22 Feb-8 Mar & TOC & GFF & -26.47 & -95.7 & $0.910 \pm 0.008$ \\
Winter composites & & & & & \\
23 Jan-6 Feb & Phen & PUF & -27.85 & 58.0 & $1.065 \pm 0.017$ \\
23 Jan-8 Mar & Phen & GFF & -28.19 & 14.7 & $1.022 \pm 0.020$ \\
23 Jan-8 Mar & Fluor & GFF & -28.48 & 58.8 & $1.066 \pm 0.014$ \\
23 Jan-8 Mar & Pyr & GFF & -27.94 & -26.8 & $0.980 \pm 0.012$ \\
23 Jan-8 Mar & B[b+k]F & GFF & -27.82 & -23.5 & $0.983 \pm 0.014$ \\
23 Jan-8 Mar & I[cd]P + B[ghi]P & GFF & -28.55 & -138.3 & $0.868 \pm 0.019$ \\
23 Jan-8 Mar & Sum of PAHs & PUF, GFF & -28.88 & -46.2 & $0.960 \pm 0.010$ \\
\hline
\end{tabular}

a Phenanthrene (Phen), fluoranthene (Fluor), pyrene (Pyr), benzo[b]fluoranthene plus benzo[k]fluoranthene $(\mathrm{B}[\mathrm{b}+\mathrm{k}] \mathrm{F})$, indeno[cd]pyrene (I[cd]P), benzo[ghi]perylene $\left(\mathrm{B}\left[\right.\right.$ ghi]P). ${ }^{\mathrm{b}} \delta^{13} \mathrm{C}$ and $\Delta^{14} \mathrm{C}$ are reported in \%o relative to VPDB and NBS oxalic acid I, respectively. ${ }^{\mathrm{c}}$ Total organic carbon (elemental carbon + organic carbon) is defined as carbon remaining after inorganic carbon has been removed by acid treatment. d Samples from both samplers were combined to achieve sufficient mass for CSRA analysis (see Table S1 in Supporting Information: http://www.atmos-chem-phys.net/9/3347/2009/acp-9-3347-2009-supplement.pdf).

property) may be affected by sampling artifacts, the ${ }^{14} \mathrm{C} /{ }^{12} \mathrm{C}$ ratio should remain intact; the physicochemical properties of these isotopologues are very similar.

Prior to sampling, filters were baked at $450^{\circ} \mathrm{C}$ for $5 \mathrm{~h}$ and PUFs were pre-cleaned by washing in a washing machine at $90^{\circ} \mathrm{C}$ without detergent, dried at $35^{\circ} \mathrm{C}$ for 4 days and Soxhlet extracted first with toluene for two days and then with acetone for one day. PUFs were thereafter dried in a desiccator with vacuum suction for one day and finally wrapped in aluminum foil and sealed in airtight plastic bags until sampling. After sampling, filters were wrapped in aluminum foil, packed into airtight plastic bags and PUFs were wrapped in aluminum foil and sealed in airtight plastic bags. All samples were first stored for several days in a refrigerator $\left(+4^{\circ} \mathrm{C}\right)$ and then in a freezer $\left(-18^{\circ} \mathrm{C}\right)$ prior to analysis.

\subsection{TOC analysis}

Total organic carbon (TOC) is here defined as the carbon remaining after inorganic carbon is removed by acid treatment (Zencak et al., 2007a). TOC analysis was conducted on 3 filter samples (Table 1). A $2.90 \mathrm{~cm}^{2}$ portion of each filter sample was treated with $37 \% \mathrm{HCl}$ fumes in a desiccator for 2 days to remove carbonates. The residual (TOC) was determined with a high-temperature catalytic elemental analyzer (Carlo Erba/Fisons, Italy) and blank corrected.

\subsection{PAH analysis}

For each 2-week sample period, $75 \%$ of each filter from the two samplers were combined for extraction resulting in 3 filter samples. For the PUFs, a combined sample was extracted for each of the two 1-week PUF sample periods from the two samplers resulting in 2 PUF extracts. The filter and PUF samples were extracted with cyclohexane in a Soxhlet apparatus. After extraction, a 5\% aliquot of the extract was spiked with deuterated PAHs (phenanthrene- $d_{10}$, fluoranthene- $d_{10}$, pyrene- $d_{10}$, and benzo[ $\left.a\right]$ pyrene- $d_{12}$, benzo $[g, h, i]$-perylene$d_{12}$ ). The remainder of the method is based on previously reported work (Mandalakis et al., 2005; Zencak et al., 2007b). Briefly, the cyclohexane extracts were reduced to $2 \mathrm{ml}$ by rotary evaporation. To purify the extracts, each was applied to a deactivated silica gel column $\left(\mathrm{SiO}_{2}-10 \% \mathrm{H}_{2} \mathrm{O}, 63\right.$ $200 \mu \mathrm{m}$ particle size, $10 \mathrm{~cm} \times 1 \mathrm{~cm}$ i.d.) and eluted with $\mathrm{n}$ hexane. The samples were further treated with a dimethylformamide (DMF-5\% water)-pentane partitioning cleanup procedure (Mandalakis et al., 2004b) to isolate PAHs from interfering aliphatic compounds. Extracts were then applied to a second deactivated silica gel column containing disodium sulfate $\left(\mathrm{Na}_{2} \mathrm{SO}_{4}\right.$, anh.) to remove water. At this point, the extracts were spiked with a co-injection standard, chrysene$d_{12}$, and analyzed by gas chromatography/mass spectrometry (Fisons 8060GC interfaced to a Fisons MD 800 mass spectrometer) with the MS operated in selective ion monitoring mode (Mandalakis et al., 2004a).

\subsection{Preparative capillary gas chromatography and ac- celerator mass spectroscopy}

The details of the Gerstel preparative capillary gas chromatography (PCGC) method used for PAH isolation and harvesting have been reported previously (Mandalakis and Gustafsson, 2003; Mandalakis et al., 2004a) and are summarized here. Ninety-five percent of each cyclohexane extract 


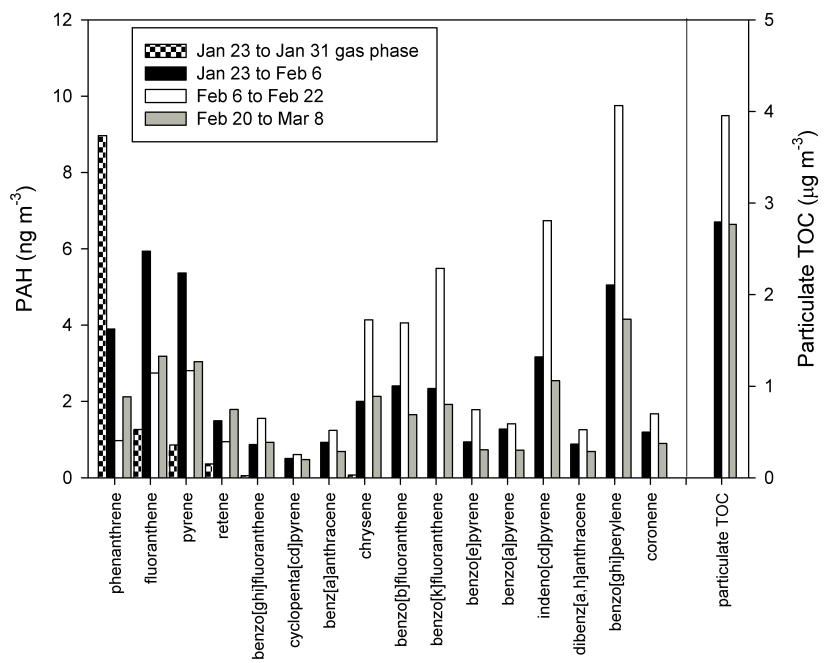

Fig. 1. Left side: Ambient concentrations of individual PAHs in Lycksele, Sweden for gas phase and particulate phases for each sample set. Right side: Particulate TOC concentration for each sample set.

was first purified as described in the PAH analysis section except for the spiking with deuterated PAHs. Each purified extract was then repeatedly injected into the PCGC system (roughly 40 injections per extract) and the PAHs listed in Table 1 were trapped separately. PAHs harvested in the glass traps were then transferred using several rinses of hexane and passed through a small column packed with $\mathrm{SiO}_{2}(4 \mathrm{~cm} \times 0.5 \mathrm{~cm}$ i.d. $)$ using hexane. A small aliquot from each trap was used to check purity and to quantify the harvested PAHs with GC-MS. Purities ranged from 92$100 \%$, with an average of $97 \%$ and yields were low at 24 $46 \%$ for all but benzo[ghi]perylene which had a yield of $15 \%$. The low yield will not impact the radiocarbon results, however, as Zencak et al showed that $\Delta^{14} \mathrm{C}$ normalized, as these were, to a $\delta^{13} \mathrm{C}$ of $-25 \%$ corrects any putative isotopic fractionation during PCGC isolation (Zencak et al., 2007c). In order to achieve sufficient mass for the CSRA method, the PAHs from the 3 filter extracts were combined after harvesting. The harvested PAHs from the 2 PUF extracts were likewise combined (Table S1 in Supporting Information: http://www.atmos-chem-phys.net/9/3347/ 2009/acp-9-3347-2009-supplement.pdf). This was the final step conducted at Stockholm University before the extracts were shipped out for further analysis.

Carbon isotope analysis was performed at the National Ocean Sciences Accelerator Mass Spectrometry (NOSAMS) facility of the Woods Hole Oceanographic Institution (USA). Acid fumigated TOC and PCGC-isolated individual PAH samples were oxidized to $\mathrm{CO}_{2}$, purified and quantified by manometry (Pearson et al., 1998). About $10 \%$ of $\mathrm{CO}_{2}$ was kept for $\delta^{13} \mathrm{C}$ analysis by isotope ratio mass spectrometry. The remaining $90 \%$ was reduced to graphite and subjected to accelerator mass spectrometry to determine the fraction of modern carbon, $f_{M}$, which is the ${ }^{14} \mathrm{C} /{ }^{12} \mathrm{C}$ ratio of the sample related to that of the reference year 1950. The reported $\Delta{ }^{14} \mathrm{C}$ uncertainty is the larger of the internal uncertainty (statistical uncertainty calculated using the number of counts measured from each AMS sample) and external uncertainty (uncertainty calculated from the reproducibility of individual analyses of a single sample) (Pearson et al., 1998). More details on radiocarbon conventions and metric, the routine AMS sample preparation and analysis procedures are available elsewhere (Zencak et al., 2007b; Klinedinst and Currie, 1999). Previous studies in our laboratory at Stockholm University have shown limited fossil and no modern carbon contamination during the pcGC method (including potential column bleed and general sample handling), with processed and unprocessed standards showing no significant difference when the uncertainty of the AMS is considered (Zencak et al., 2007c). TOC blanks comprised roughly $1-3 \%$ of the sample TOC and the TOC radiocarbon results were blank corrected. This resulted in a $0.3-1.2 \%$ change in the $f_{M}$.

\section{Results and discussion}

\subsection{Ambient concentrations}

Previously reported work from the Lycksele winter 2006 campaign has demonstrated that a combination of wintertime residential wood burning and traffic emissions with stable atmospheric conditions can result in locally high PM events (Krecl et al., 2007, 2008b). The measurements in the current study were collected during an overlapping time period as these Krecl et al. studies, but on completely different time scales. The ambient concentrations reported here are based on integrating 1-2 week sample collection periods, thus any extreme short-duration events are effectively smoothed out over the collection interval.

Systematically high TOC and PAH concentrations were observed during the 2006 winter season in Lycksele, Sweden (Fig. 1). Gas phase samples were only collected in the first sampling period, but the cold winter temperatures ensured that the volatile component was important only for phenanthrene, the most volatile of the measured PAHs; other measured PAHs were predominantly present in the particulate phase. Despite the 14-day sampling integration, the three filter samples had different PAH concentrations and fingerprints. The lower molecular weight PAHs (fluoranthene and pyrene) have relatively higher concentrations in the first sampling period (23 January-6 February) while the higher molecular weight PAHs (chrysene to coronene) were higher in the second sampling period (6-22 February). The particulate TOC concentration for the three sampling periods parallels the trend seen for the higher molecular weight PAHs. To put these PAH concentrations in perspective, Table 2 compiles PAH concentrations from several previously reported studies of areas impacted by biomass burning (Sheesley et 
Table 2. Concentrations of representative PAH $\left(\mathrm{ng} \mathrm{m}^{-3}\right)$ from studies in areas impacted by biomass burning.

\begin{tabular}{|c|c|c|c|c|c|c|}
\hline \multirow{2}{*}{$\begin{array}{l}\text { Location } \\
\mathrm{PAH}^{\mathrm{a}} / \text { Season }\end{array}$} & \multirow{2}{*}{$\begin{array}{c}\text { North Carolina, USA } \\
\\
\text { 2003-2004 } \\
\text { winter range }\end{array}$} & \multirow{2}{*}{$\begin{array}{c}\text { San Joaquin Valley, CA USA } \\
\text { 1995-1996 winter } 2 \\
\text { event range }\end{array}$} & \multicolumn{2}{|c|}{$\begin{array}{l}\text { Lycksele, Sweden } \\
\text { (2006 is current study) }\end{array}$} & \multirow{2}{*}{$\begin{array}{l}\text { Delhi, Kolkata and } \\
\text { Mumbai, India }^{\mathrm{f}} \\
\text { 2001-2002 } \\
\text { winter range }\end{array}$} & \multirow{2}{*}{$\begin{array}{c}\text { Augsburg, } \\
\text { Germany } \\
2003-2004 \\
\text { winter }\end{array}$} \\
\hline & & & $\begin{array}{c}2002^{\mathrm{d}} \\
\text { winter range }\end{array}$ & $\begin{array}{l}2006^{\mathrm{e}} \\
\text { winter }\end{array}$ & & \\
\hline Phen & $\mathrm{NA}^{\mathrm{h}}$ & NA & $22.0-40.0$ & 11.3 & NA & NA \\
\hline Fluor & NA & $0.4-2.5$ & $7.5-17.0$ & 5.2 & NA & NA \\
\hline Pyr & NA & $0.5-3.3$ & $7.4-18.0$ & 4.6 & NA & NA \\
\hline $\mathrm{B}[\mathrm{b}] \mathrm{F}$ & $0.3-0.8$ & $2.5-10.7$ & $2.3-6.2$ & 2.7 & $6.7-53.6$ & NA \\
\hline $\begin{array}{l}\mathrm{B}[\mathrm{k}] \mathrm{F} \\
\text { sum } \mathrm{B}[\mathrm{b}+\mathrm{k}] \mathrm{F}\end{array}$ & $\mathrm{ND}^{\mathrm{i}}-0.4$ & $2.1-8.7$ & $0.8-2.0$ & 3.2 & $5.6-40.9$ & $\begin{array}{l}\text { NA } \\
4.0\end{array}$ \\
\hline $\mathrm{I}[\mathrm{cd}] \mathrm{P}$ & $0.2-0.5$ & $2.6-6.8$ & $1.6-3.8$ & 4.2 & $3.6-18.5$ & 0.6 \\
\hline $\mathrm{B}$ [ghi]P & $0.4-0.7$ & $3.5-9.8$ & $2.0-3.7$ & 6.3 & NA & 0.8 \\
\hline
\end{tabular}

a Phenanthrene (Phen), fluoranthene (Fluor), pyrene (Pyr), benzo[b]fluoranthene (B[b]F), benzo[k]fluoranthene (B[k]F), indeno[cd]pyrene (I[cd]P), benzo[ghi]perylene (B[ghi]P). ${ }^{\mathrm{b}}$ Sheesley et al. (2007), 4 semi-urban sites, particle phase, $\mathrm{PM}_{2.5}$ fraction. ${ }^{\mathrm{c}}$ Schauer and Cass (2000) 2 sites, 2 winter events, particle phase, $\mathrm{PM}_{2.5}$ fraction. ${ }^{\mathrm{d}}$ Johansson et al. (2004), Norrmalm and Forsdala residential neighborhoods, gas + particle phases, $\mathrm{PM}_{10}$ fraction. ${ }^{\mathrm{e}}$ gas + particle phases, TSP. ${ }^{\mathrm{f}}$ Chowdhury et al. (2007), particle phase, $\mathrm{PM}_{2.5}$ fraction. ${ }^{\mathrm{g}}$ Schnelle-Kreis et al. (2007), particle phase, $\mathrm{PM}_{2.5}$ fraction. ${ }^{\mathrm{h}} \mathrm{NA}$ : not available. ${ }^{\mathrm{i}} \mathrm{ND}$ : not detectable.

al., 2007; Schnelle-Kreis et al., 2007; Chowdhury et al., 2007; Schauer and Cass, 2000). The 2006 winter measurements (this study) are roughly in the same range as those reported for the same town in 2002. However, the low/high molecular weight PAH ratio was higher in 2002 than in 2006. Atmospheric levels in Lycksele are in the range of high PM event-level concentrations measured in the San Joaquin Valley, CA, USA (Schauer and Cass, 2000), but significantly lower than winter measurements in Indian cities (Chowdhury et al., 2007). Using chemical mass balance modeling with organic tracers, the contribution of biomass burning (wood fuel) was estimated to be $42 \%$ of the ambient $\mathrm{PM}_{2.5}$ mass concentration in San Joaquin Valley (Schauer and Cass, 2000) and 12 to $20 \%$ in Indian cities during wintertime (Chowdhury et al., 2007).

\subsection{Carbon isotope results}

The high ambient PAH concentrations in Lycksele made it an ideal site for this CSRA-based source apportionment study. The five individual/paired PAHs of highest concentration were successfully isolated, harvested and quantified for radiocarbon content (Table 1). Results of ${ }^{13} \mathrm{C}$ isotope analysis are presented as $\delta^{13} \mathrm{C}$ values relative to the Vienna Pee Dee Belemnite (VPDB) standard (Coplen, 1996). Radiocarbon data are reported as $\Delta^{14} \mathrm{C}$ and fraction modern $\left(f_{M}\right)$ relative to NBS Oxalic Acid I and have been corrected for carbon blank and isotopic fractionation both in the environment and during sample preparation using a $\delta^{13} \mathrm{C}$ of $-25 \%$ o as described elsewhere (Klinedinst and Currie, 1999; Stuiver and Polach, 1977; Zencak et al., 2007c). Above-ground nuclear testing in the mid-twentieth century nearly doubled atmospheric $\Delta^{14} \mathrm{C}$ values, but since that time this radiogenic "bomb spike" signal has been consistently decreasing (Levin et al., 2003), which means that biomass which grows over many years, such as trees, will have a higher $\Delta^{14} \mathrm{C}$ than contemporary $\mathrm{CO}_{2}$. Therefore, contemporary $\mathrm{CO}_{2}$ and freshly produced biomass has a $\Delta{ }^{14} \mathrm{C}$ value of $+70 \%$ (Levin and Kromer, 2004), while contemporary wood fuel sources have been reported to have a well-constrained $\Delta{ }^{14} \mathrm{C}$ between $+225 \%$ and $+218 \%$ (Currie et al., 1999; Klinedinst and Currie, 1999; Zencak et al., 2007a; Szidat et al., 2004b, 2007) and fossil fuel sources have a $\Delta{ }^{14} \mathrm{C}$ of $-1000 \%$.

For a case such as wintertime PAHs in Lycksele, biogenic emissions are not likely due to the very low air temperatures that reduce biological activity and volatile organic carbon emissions. Snow-covered ground during the entire sampling period prevented the occurrence of grass fires in the region and incineration of household vegetable waste is not a common practice in the area. The $\Delta^{14} \mathrm{C}-\mathrm{PAH}$ and -TOC signals are constrained to -138 to $59 \%$ and demonstrate that the modern carbon source is dominant for both TOC and individual PAHs. Wood fuel burning is assumed to be the dominant source of non-fossil PAHs in Lycksele. However, a fossil carbon and PAH source, most likely motor vehicle exhaust based on previous studies in the area (Krecl et al., 2008a, b), is present in all samples. The $\Delta^{14} \mathrm{C}$ for bulk TOC had a more limited range ( -96 to $-24 \%$ ) than the $\Delta^{14} \mathrm{C}$ range for PAHs $\left(-138\right.$ to $59 \%$ ), with fluoranthene the most enriched in ${ }^{14} \mathrm{C}$ and the paired indeno[cd]pyrene plus benzo[ghi]perylene the most depleted.

The ${ }^{13} \mathrm{C}$ values in Lycksele are slightly more enriched in the TOC $(-26.41 \%$ o to $-26.68 \%$ o $)$ than in the PAHs $(-27.82 \%$ o to $-28.88 \%$ o); the PAHs are in the same range as 


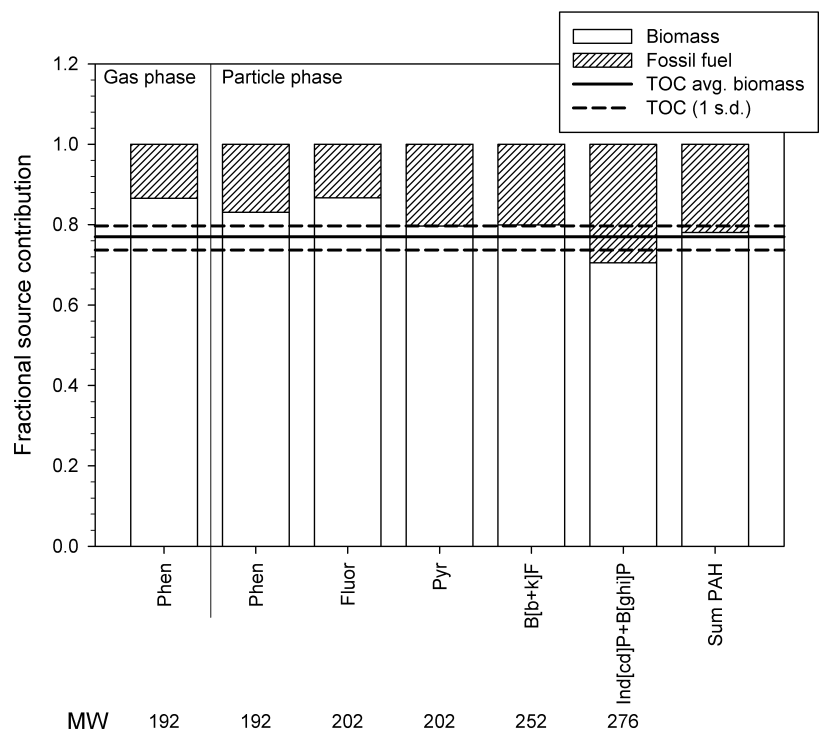

Fig. 2. Fractional contributions of biomass and fossil fuel combustion sources for individual PAHs and sum of PAHs in Lycksele. Average \pm 1 s.d. contribution of biomass burning to TOC for the three, two-week samples is displayed as horizontal lines. The molecular weight (MW) for each individual/paired PAH is listed at the bottom for comparison.

reported for European background sites (Mandalakis et al., 2005). Additionally, the TOC and all the PAH $\delta^{13} \mathrm{C}$ values are within the reported range for terrestrial $\mathrm{C}_{3}$ plant combustion (Zencak et al., 2007a). It should be noted that although $\Delta{ }^{14} \mathrm{C}$ values reported in the literature are commonly corrected for fractionation (Stuiver and Polach, 1977), the same is not true of $\delta^{13} \mathrm{C}$ values. Therefore $\delta^{13} \mathrm{C}$ results derived from samples prepared using PCGC may be biased if the entire peak was not collected (Zencak et al., 2007c).

\subsection{Radiocarbon-based source apportionment}

An isotopic mass balance equation was applied to the TOC and PAH $\Delta{ }^{14} \mathrm{C}$ results to calculate fractional contribution of wood burning ( $\left.f_{\text {biomass }}\right)$ and fossil fuel combustion $\left(f_{\text {fossil }}=1-f_{\text {biomass }}\right)$ (Reddy et al., 2002; Currie et al., 1999; Mandalakis et al., 2004a; Reddy et al., 2003):

$\Delta{ }^{14} \mathrm{C}_{\text {sample }}=\Delta^{14} \mathrm{C}_{\text {biomass }} f_{\text {biomass }}+\Delta{ }^{14} \mathrm{C}_{\text {fossil }}\left(1-f_{\text {biomass }}\right)$

In the above equation, $\Delta^{14} \mathrm{C}_{\text {sample }}$ represents the radiocarbon results presented in Table 1 for TOC and PAHs. The $\Delta{ }^{14} C_{\text {biomass }}$ in the present study is set to $+218 \%$ o while the $\Delta{ }^{14} \mathrm{C}_{\text {fossil }}$ is $-1000 \%$ (see above discussion). The resulting $f_{\text {biomass }}$ are presented in Fig. 2 . The PAH $f_{\text {biomass }}$ results represent the full 6-week sampling period for all species except gas-phase phenanthrene (2-week sample), while the TOC average $f_{\text {biomass }} \pm$ one standard deviation is included in Fig. 2.

The $f_{\text {biomass }}$ ranges from $71-87 \%$ for all PAHs and the average for TOC is $77 \pm 3 \%$. Hence, TOC is in the middle of the $f_{\text {biomass }}$ range for the measured PAHs. Several previous studies have reported the $f_{\text {biomass }}$ for pooled, compoundclass specific radiocarbon analysis (CCSRA) of PAHs and CSRA of household soot and NIST SRM 1649a (urban dust from Washington, D.C., USA) (see Table 3). The SRM and soot were both solid/dust samples while the remaining represent filter-based samples. The Croatian and Greek values represent summer conditions whereas the Southern Sweden $f_{\text {biomass }}(50 \%)$ is a multi-year average; a winter event at the same Southern Sweden site had an $f_{\text {biomass }}$ for TOC of 75 85\% (Zencak et al., 2007a), and the difference between the $\mathrm{PAH}$ annual average and the winter TOC illustrates the impact of seasonal sources such as RWC. Table 3 also illustrates the differences among RWC contribution across Europe and beyond. In a study in Tokyo, particulate CCSRA-PAHs in the $\mathrm{PM}_{10}$ fraction were split into low and high molecular weight fractions with little seasonal differences. Road traffic emissions might be expected to dominate in and around a megacity like Tokyo, and therefore it is surprising to see the high fraction of PAH from biomass combustion in both summer and winter. It was suggested to reflect incineration of household wastes, rich in vegetables. The $f_{\text {biomass }}$ calculated for Lycksele is much higher than all three of these previously reported CCSRA-PAH studies and the CSRA from NIST SRM 1649a, but roughly the same as the winter TOC from southern Sweden. The $f_{\text {biomass }}$ of PAHs from this study plus the $f_{\text {biomass }}$ of TOC from Southern Sweden (Zencak et al., 2007a) indicate the dominance of RWC during winter in the boreal zone and the importance of not extrapolating beyond studied seasons and regions.

To evaluate the isotopic (and source) heterogeneity between gas phase and particulate PAHs, this study afforded radiocarbon analysis on phenanthrene in both phases. The $f_{\text {biomass }}$ of gaseous and particulate phenanthrene were indistinguishable within three times the uncertainty in Lycksele. Although the gas and particulate phase phenanthrene samples for radiocarbon were not synchronous $(23$ January-6 February for gas phase, and 23 January-6 February +22 February- 8 March for particulate phase, see Table S1 at http://www.atmos-chem-phys.net/9/3347/2009/ acp-9-3347-2009-supplement.pdf), the TOC radiocarbon results for the three, two-week periods show stability in the source contributions despite differences in concentration ( $\mathrm{Ta}-$ ble 1). Based on the imperfect comparison in this study, the partitioning of phenanthrene between the gaseous and particulate phase is apparently dominated by ambient conditions under these winter-time conditions and is less impacted by differences in the physical or chemical characteristics of RWC or motor vehicle exhaust.

\subsection{Fraction biomass and molecular weight}

We further sought to investigate isotopic heterogeneity as a function of PAH vapor pressure and/or size, however the number of samples inhibits statistical analysis. In 
Table 3. Fraction biomass contribution from isotopic mass balance in percentage. Unless season is noted, an annual average should be assumed.

\begin{tabular}{|c|c|c|c|c|c|c|c|c|c|}
\hline Location, season & PAHs & PAH-low MW & PAH- high MW & Phen & Fluor & Pyr & $\mathrm{B}[\mathrm{b}, \mathrm{j}, \mathrm{k}] \mathrm{F}$ & $\mathrm{B}[\mathrm{ghi}] \mathrm{P}\left(+\mathrm{I}[\mathrm{cd}] \mathrm{P}^{\mathrm{f}}\right)$ & TOC \\
\hline Southern Sweden & $50^{\mathrm{a}}$ & & & & & & & & $75-85^{b}$ \\
\hline Croatia, summer ${ }^{\mathrm{a}}$ & 9 & & & & & & & & \\
\hline Greece, summer ${ }^{\mathrm{a}}$ & 7 & & & & & & & & \\
\hline Western Balkans ${ }^{c}$ & $35-65$ & & & & & & & & \\
\hline Tokyo, summer ${ }^{\mathrm{d}}$ & & $17-20$ & $38-43$ & & & & & & \\
\hline Tokyo, winter ${ }^{\mathrm{d}}$ & & $24-28$ & $27-31$ & & & & & & \\
\hline NIST SRM $1649 \mathrm{a}^{\mathrm{e}}$ & $3-6$ & & & 3.0 & 4.7 & 3.7 & 6.2 & 6.4 & \\
\hline Household soot ${ }^{\mathrm{f}}$ & & & & 70 & 54 & 59 & & & \\
\hline $\begin{array}{l}\text { Lycksele, Sweden, } \\
\text { winter }^{\mathrm{g}} \\
\text { (current study) }\end{array}$ & 78 & & & $83-87$ & 87 & 80 & 80 & 71 & 77 \\
\hline
\end{tabular}

${ }^{a}$ Mandalakis et al. (2005). ${ }^{b}$ Zencak et al. (2007a), winter season only. ${ }^{c}$ Zencak et al. (2007b). ${ }^{d}$ Kumata et al. (2006) The table includes only the $\mathrm{PM}_{10}$ (particulate matter $<10 \mu \mathrm{m}$ in diameter) data. ${ }^{\mathrm{e}}$ Reddy et al. (2002) range indicates range of 7 individual PAH. Selected PAH from the 7 are included in the table. ${ }^{\mathrm{f}}$ Reddy et al. (2003). $\mathrm{g}$ Current study. Value in PAHs column represent sample of 22 PAHs, not a calculation from CSRA.

Fig. 2, there is a small decrease in $f_{\text {biomass }}$ with increasing molecular weight for the five compounds/compound pairs analyzed here. The $f_{\text {biomass }}$ of phenanthrene, fluoranthene, pyrene and benzo[b+k]fluoranthene are relatively similar, and it is particularly the pair of $\mathrm{MW}$ 276 PAHs (indeno[cd]pyrene plus benzo[ghi]perylene) that have a much lower $f_{\text {biomass. }}$ At $71 \%$, the $f_{\text {biomass }}$ of indeno[cd]pyrene plus benzo[ghi]perylene is $16 \%$ lower than gas phase phenanthrene and fluoranthene and $9 \%$ lower than benzo[b+k]fluoranthene. The results are broadly consistent with a PAH fingerprint skewed toward higher masses for high-temperature combustion processes such as fossil fuel combustion. In fact, both indeno[cd]pyrene and benzo[ghi]perylene have been used in organic molecular marker-chemical mass balance models (MM-CMB) to apportion the contribution of gasolinepowered motor vehicle exhaust to atmospheric particulate organic carbon (Chow et al., 2007; Sheesley et al., 2007). Figure S1 (http://www.atmos-chem-phys.net/9/3347/ 2009/acp-9-3347-2009-supplement.pdf) illustrates that the $\mathrm{PAH} / \mathrm{OC}$ ratio for benzo[ghi]perylene, in particular, is much higher for the two gasoline-powered motor vehicle exhaust average profiles (Lough et al., 2007; Rogge et al., 1993) in comparison to the same ratio for wood smoke emission profiles (Lee et al., 2005; Schauer et al., 2001; Fine et al., $2002,2004)$ and reported diesel-powered motor vehicle exhaust (Rogge et al., 1993; Lough et al., 2007; Riddle et al., 2007). A further exploration of the apportionment of OC based on published PAH/OC ratios for motor vehicle exhaust is included in the Supplementary Material. The results of this calculation of ambient fossil OC from ambient fossil indeno[cd]pyrene plus benzo[ghi]perylene concentrations indicate that the published gasoline motor vehicle profiles are a better fit for this Lycksele dataset. Vehicle registration for Lycksele kommun, which includes both the city and surrounding area, indicates $86 \%$ gasoline and $14 \%$ diesel (H. Granlund and K. Fjällstedt, personal communication, 2009). These fleet values also cannot conclusively predict the gasoline/diesel split for PAHs but combined with the available emission profile data and CSRA results gives an indication of the potential importance of gasoline motor vehicle exhaust for Lycksele PAHs.

\subsection{Source contribution to ambient loadings}

The mean contribution of wood combustion to ambient TOC was $2.4 \mu \mathrm{g} \mathrm{m}^{-3}$ whereas fossil fuel combustion, most likely traffic emissions, accounted for $0.7 \mu \mathrm{g} \mathrm{m}^{-3}$ in the period 23 January-8 March. The contribution of RWC to phenanthrene was 7.8 and $1.9 \mathrm{ng} \mathrm{m}^{-3}$, while traffic emissions contributed 1.2 and $0.4 \mathrm{ng} \mathrm{m}^{-3}$ for gas and particle phase, respectively. For fluoranthene, pyrene, benzo[b+k]fluoranthene and indeno[cd]pyrene plus benzo[ghi]perylene the RWC contributions were $3.4,2.9,4.8$ and $7.5 \mathrm{ng} \mathrm{m}^{-3}$, respectively. The motor vehicle contributions were $0.5,0.7,1.2$ and $3.1 \mathrm{ng} \mathrm{m}^{-3}$, respectively. This illustrates one of the advantages of CSRA, which can be tailored to define source contributions of specific compounds like PAHs, which are of interest as carcinogenic compounds and as source tracers.

\section{Conclusions}

The results of the CSRA analysis in Lycksele conclusively demonstrate that high ambient concentrations of PAHs across the molecular weight spectrum, and TOC in general, are 
a result of RWC. Therefore, a significant reduction of carcinogenic atmospheric PAHs in Lycksele, and likely for many similar such towns in the boreal zone, would require targeting RWC emissions. With biomass burning contributions ranging from $87 \%$ for fluoranthene to $71 \%$ for ideno[cd]pyrene plus benzo[ghi]perylene, the CSRA shows that RWC contribution is dominant, but not uniform for all PAHs. Any decrease in RWC may have a larger impact on the lower molecular weight PAHs, as these appear to have a higher $f_{\text {biomass }}$, based on the limited results in the current study. CCSRA has been used in implicating RWC for total PAHs, however, the current work illustrates that it cannot be assumed that the contribution of RWC would be uniform; this should not be surprising as emission source testing has demonstrated differences in PAH profiles.

For this system with two dominant local source factors (Krecl et al., 2008a), the CSRA could stand alone to separate the RWC and local traffic emissions. For Lycksele, enhanced contribution of fossil fuel for the MW 276 PAHs as determined from using CSRA instead of CCSRA coupled with emission profiles and fleet numbers suggests that gasoline-powered motor vehicle exhaust contributes more to fossil PAHs in Lycksele than diesel exhaust. In a more complicated system, CSRA would add a valuable additional tool when used in conjunction with other source apportionment and chemical characterization methods.

Edited by: A. S. H. Prevot

\section{References}

Bench, G., Fallon, S., Schichtel, B., Malm, W., and McDade, C.: Relative contributions of fossil and contemporary carbon sources to $\mathrm{PM}_{2.5}$ aerosols at nine Interagency Monitoring for Protection of Visual Environments (IMPROVE) network sites, J. Geophys. Res.-Atmos., 112, D10205, doi:10.1029/2006JD007708, 2007.

Benner, B. A., Wise, S. A., Currie, L. A., Klouda, G. A., Klinedinst, D. B., Zweidinger, R. B., Stevens, R. K., and Lewis, C. W.: Distinguishing the contributions of residential wood combustion and mobile source emissions using relative concentrations of dimethylphenanthrene isomers, Environ. Sci. Technol., 29(9), 2382-2389, 1995.

Breivik, K., Vestreng, V., Rozovskaya, O., and Pacyna, J. M.: Atmospheric emissions of some POPs in Europe: a discussion of existing inventories and data needs, Environ. Sci. Policy, 9(7-8), 663-674, doi:10.1016/j.envsci.2006.09.001, 2006.

Broman, D., Naf, C., and Zebuhr, Y.: Long-term high-volume and low-volume air sampling of polychlorinated dibenzopara-dioxins and dibenzofurans and polycyclic aromatichydrocarbons along a transect from urban to remote areas on the Swedish Baltic Coast, Environ. Sci. Technol., 25(11), 18411850, 1991.

Busby, W. F., Smith, H., Plummer, E. F., Lafleur, A. L., Mulder, P. P. J., Boere, B. B., Cornelisse, J., and Lugtenburg, J.: Mutagenicity of cyclopenta-fused polynuclear aromatic hydrocarbons and a non-polar fraction from a fuel combustion sam- ple in a Salmonella forward mutation assay without exogenous metabolic activation, Mutation Research-Genetic Toxicology and Environmental Mutagenesis, 391(3), 117-125, 1997.

Choi, H., Jedrychowski, W., Spengler, J., Camann, D. E., Whyatt, R. M., Rauh, V., Tsai, W. Y., and Perera, F. P.: International studies of prenatal exposure to polycyclic aromatic hydrocarbons and fetal growth, Environ. Health Perspect., 114(11), 1744-1750, 2006.

Chow, J. C., Watson, J. G., Lowenthal, D. H., Chen, L. W. A., Zielinska, B., Mazzoleni, L. R., and Magliano, K. L.: Evaluation of organic markers for chemical mass balance source apportionment at the Fresno Supersite, Atmos. Chem. Phys., 7, 17411754, 2007, http://www.atmos-chem-phys.net/7/1741/2007/.

Chowdhury, Z., Zheng, M., Schauer, J. J., Sheesley, R. J., Salmon, L. G., Cass, G. R., and Russell, A. G.: Speciation of ambient fine organic carbon particles and source apportionment of $\mathrm{PM}_{2.5}$ in Indian cities, J. Geophys. Res.-Atmos., 112, D15, doi:10.1029/2007JD008386, 2007.

Coplen, T. B.: New guidelines for reporting stable hydrogen, carbon and oxygen isotope-ratio data, Geochim. Cosmochim. Acta, 60, 3359-3360, 1996.

Currie, L. A., Klouda, G. A., Benner, B. A., Garrity, K., and Eglinton, T. I.: Isotopic and molecular fractionation in combustion; three routes to molecular marker validation, including direct molecular 'dating' (GC/AMS), Atmos. Environ., 33(17), 27892806, 1999.

Eglinton, T. I., Aluwihare, L. I., Bauer, J. E., Druffel, E. R. M., and McNichol, A. P.: Gas chromatographic isolation of individual compounds from complex matrices for radiocarbon dating, Anal. Chem., 68(5), 904-912, 1996.

Hays, M. D., Smith, N. D., Kinsey, J., Dong, Y. J., and Kariher, P.: Polycyclic aromatic hydrocarbon size distributions in aerosols from appliances of residential wood combustion as determined by direct thermal desorption - GC/MS, J. Aerosol Sci, 34(8), 1061-1084, 2003.

Hedberg, E. and Johansson, C.: Is levoglucosan a suitable quantitative tracer for wood burning? Comparison with receptor modeling on trace elements in Lycksele, Sweden, J. Air Waste Manage. Assoc., 56(12), 1669-1678, 2006.

Hildemann, L. M., Klinedinst, D. B., Klouda, G. A., Currie, L. A., and Cass, G. R.: Sources Of Urban Contemporary Carbon Aerosol, Environ. Sci. Technol., 28(9), 1565-1576, 1994.

Jaeckels, J. M., Bae, M. S., and Schauer, J. J.: Positive Matrix Factorization (PMF) analysis of molecular marker measurements to quantify the sources of organic aerosols, Environ. Sci. Technol., 41(16), 5763-5769, 2007.

Johansson, C., Hedberg, E., Olivares, G., et al.: Measurements and calculations of the effect of wood burning on air pollution levels. Part I. Lycksele, Department of Applied Environmental Science, Stockholm University, Stockholm, SwedenITM report124, 2004.

Jordan, T. B., Seen, A. J., Jacobsen, G. E., and Gras, J. L.: Radiocarbon determination of woodsmoke contribution to air particulate matter in Launceston, Tasmania, Atmos. Environ., 40(14), 2575-2582, 2006.

Klinedinst, D. B. and Currie, L. A.: Direct quantification of $\mathrm{PM}_{2.5}$ fossil and biomass carbon within the Northern Front Range Air Quality Study's domain, Environ. Sci. Technol., 33(23), 41464154, 1999. 
Krecl, P., Strom, J., and Johansson, C.: Carbon content of atmospheric aerosols in a residential area during the wood combustion season in Sweden, Atmos. Environ., 41(33), 6974-6985, doi:10.1016/j.atmosenv.2007.06.025, 2007.

Krecl, P., Hedberg Larsson, E., Ström, J., and Johansson, C.: Contribution of residential wood combustion and other sources to hourly winter aerosol in Northern Sweden determined by positive matrix factorization, Atmos. Chem. Phys., 8, 3639-3653, 2008a, http://www.atmos-chem-phys.net/8/3639/2008/.

Krecl, P., Strom, J., and Johansson, C.: Diurnal variation of atmospheric aerosol during the wood combustion season in Northern Sweden, Atmos. Environ., 42(18), 4113-4125, doi:10.1016/j.atmosenv.2008.01.026, 2008b.

Kumata, H., Uchida, M., Sakuma, E., Uchida, T., Fujiwara, K., Tsuzuki, M., Yoneda, M., and Shibata, Y.: Compound class specific C-14 analysis of polycyclic aromatic hydrocarbons associated with $\mathrm{PM}_{10}$ and $\mathrm{PM}_{1.1}$ aerosols from residential areas of suburban Tokyo, Environ. Sci. Technol., 40(11), 3474-3480, 2006.

Larsen, R. K. and Baker, J. E.: Source apportionment of polycyclic aromatic hydrocarbons in the urban atmosphere: A comparison of three methods, Environ. Sci. Technol., 37(9), 1873-1881, doi:10.1021/es0206184, 2003.

Levin, I., Kromer, B., Schmidt, M., and Sartorius, H.: A novel approach for independent budgeting of fossil fuel $\mathrm{CO}_{2}$ over Europe by $\left(\mathrm{CO}_{2}\right)-\mathrm{C}-14$ observations, Geophys. Res. Lett., 30, 23, doi:10.1029/2003GL018477, 2003.

Levin, I. and Kromer, B.: The tropospheric (CO2)-C-14 level in mid-latitudes of the Northern Hemisphere (1959-2003), Radiocarbon, 46(3), 1261-1272, 2004.

Lima, A. L. C., Farrington, J. W., and Reddy, C. M.: Combustionderived polycyclic aromatic hydrocarbons in the environment A review, Environ. Forensics, 6(2), 109-131, 2005.

Lough, G. C. and Schauer, J. J.: Sensitivity of source apportionment of urban particulate matter to uncertainty in motor vehicle emissions profiles, J. Air Waste Manage. Assoc., 57(10), 1200-1213, 2007.

Mandalakis, M. and Gustafsson, O.: Optimization of a preparative capillary gas chromatography-mass spectrometry system for the isolation and harvesting of individual polycyclic aromatic hydrocarbons, J. Chromatogr. A, 996(1-2), 163-172, 2003.

Mandalakis, M., Gustafsson, O., Reddy, C. M., and Li, X.: Radiocarbon apportionment of fossil versus biofuel combustion sources of polycyclic aromatic hydrocarbons in the Stockholm metropolitan area, Environ. Sci. Technol., 38(20), 5344-5349, 2004a.

Mandalakis, M., Zebuhr, Y., and Gustafsson, O.: Efficient isolation of polyaromatic fraction from aliphatic compounds in complex extracts using dimethylformamide-pentane partitionings, J. Chromatogr. A, 1041(1-2), 111-117, 2004b.

Mandalakis, M., Gustafsson, O., Alsberg, T., Egeback, A. L., Reddy, C. M., Xu, L., Klanova, J., Holoubek, I., and Stephanou, E. G.: Contribution of biomass burning to atmospheric polycyclic aromatic hydrocarbons at three European background sites, Environ. Sci. Technol., 39(9), 2976-2982, 2005.

McDonald, J. D., Zielinska, B., Fujita, E. M., Sagebiel, J. C., Chow, J. C., and Watson, J. G.: Emissions from charbroiling and grilling of chicken and beef, J. Air Waste Manage. Assoc., 53(2), 185194, 2003.

Pearson, A., McNichol, A. P., Schneider, R. J., Von Reden, K.
F., and Zheng, Y.: Microscale AMS C-14 measurement at NOSAMS, Radiocarbon, 40(1), 61-75, 1998.

Ravindra, K., Sokhi, R., and Van Grieken, R.: Atmospheric polycyclic aromatic hydrocarbons: Source attribution, emission factors and regulation, Atmos. Environ., 42(13), 2895-2921, doi:10.1016/j.atmosenv.2007.12.010, 2008.

Reddy, C. M., Pearson, A., Xu, L., McNichol, A. P., Benner, B. A., Wise, S. A., Klouda, G. A., Currie, L. A., and Eglinton, T. I.: Radiocarbon as a tool to apportion the sources of polycyclic aromatic hydrocarbons and black carbon in environmental samples, Environ. Sci. Technol., 36(8), 1774-1782, 2002.

Reddy, C. M., Xu, L., and O'Connor, R.: Using radiocarbon to apportion sources of polycyclic aromatic hydrocarbons in household soot, Environ. Forensics, 4(3), 191-197, 2003.

Sauvain, J. J., Duc, T. V., and Guillemin, M.: Exposure to carcinogenic polycyclic aromatic compounds and health risk assessment for diesel-exhaust exposed workers, Int. Arch. Occ. Env. Hea., 76(6), 443-455, 2003.

Schauer, J. J. and Cass, G. R.: Source apportionment of wintertime gas-phase and particle-phase air pollutants using organic compounds as tracers, Environ. Sci. Technol., 34(9), 1821-1832, 2000.

Schauer, J. J., Kleeman, M. J., Cass, G. R., and Simoneit, B. R. T.: Measurement of emissions from air pollution sources. 3. C1-C- 29 organic compounds from fireplace combustion of wood, Environ. Sci. Technol., 35(9), 1716-1728, 2001.

Schauer, J. J., Kleeman, M. J., Cass, G. R., and Simoneit, B. R. T.: Measurement of emissions from air pollution sources. 5. C-1-C32 organic compounds from gasoline-powered motor vehicles, Environ. Sci. Technol., 36(6), 1169-1180, 2002.

Schnelle-Kreis, J., Sklorz, M., Orasche, J., Stolzel, M., Peters, A., and Zimmermann, R.: Semi volatile organic compounds in ambient $\mathrm{PM}_{2.5}$. Seasonal trends and daily resolved source contributions, Environ. Sci. Technol., 41(11), 3821-3828, 2007.

Schwarze, P. E., Ovrevik, J., Hetland, R. B., Becher, R., Cassee, F. R., Lag, M., Lovik, M., Dybing, E., and Refsnes, M.: Importance of size and composition of particles for effects on cells in vitro, Inhalation Toxicology, 19, 17-22, 2007.

Sheesley, R. J., Schauer, J. J., Zheng, M., and Wang, B.: Sensitivity of molecular marker-based CMB models to biomass burning source profiles, Atmos. Environ., 41(39), 9050-9063, 2007.

Stuiver, M. and Polach, H. A.: Reporting Of C-14 Data - Discussion, Radiocarbon, 19(3), 355-363, 1977.

Szidat, S., Jenk, T. M., Gaggeler, H. W., Synal, H. A., Fisseha, R., Baltensperger, U., Kalberer, M., Samburova, V., Reimann, S., Kasper-Giebl, A., and Hajdas, I.: Radiocarbon (C-14)-deduced biogenic and anthropogenic contributions to organic carbon (OC) of urban aerosols from Zurich, Switzerland, Atmos. Environ., 38(24), 4035-4044, 2004a.

Szidat, S., Jenk, T. M., Gaggeler, H. W., Synal, H. A., Fisseha, R., Baltensperger, U., Kalberer, M., Samburova, V., Wacker, L., Saurer, M., Schwikowski, M., and Hajdas, I.: Source apportionment of aerosols by C-14 measurements in different carbonaceous particle fractions, Radiocarbon, 46(1), 475-484, 2004b.

Szidat, S., Prevot, A. S. H., Sandradewi, J., Alfarra, M. R., Synal, H. A., Wacker, L., and Baltensperger, U.: Dominant impact of residential wood burning on particulate matter in Alpine valleys during winter, Geophys. Res. Lett., 34, L05820, doi:10.1029/2006GL028325, 2007. 
Yan, B. Z., Abrajano, T. A., Bopp, R. F., Chaky, D. A., Benedict, L. A., and Chillrud, S. N.: Molecular tracers of saturated and polycyclic aromatic hydrocarbon inputs into Central Park Lake, New York City, Environ. Sci. Technol., 39(18), 7012-7019, 2005.

Yunker, M. B., Macdonald, R. W., Vingarzan, R., Mitchell, R. H., Goyette, D., and Sylvestre, S.: PAHs in the Fraser River basin: a critical appraisal of PAH ratios as indicators of PAH source and composition, Org. Geochem., 33(4), 489-515, 2002.

Zencak, Z., Elmquist, M., and Gustafsson, O.: Quantification and radiocarbon source apportionment of black carbon in atmospheric aerosols using the CTO-375 method, Atmos. Environ., 41(36), 7895-7906, 2007a.
Zencak, Z., Klanova, J., Holoubek, I., and Gustafsson, O.: Source apportionment of atmospheric PAHs in the western balkans by natural abundance radiocarbon analysis, Environ. Sci. Technol., 41(11), 3850-3855, 2007b.

Zencak, Z., Reddy, C. M., Teuten, E. L., Xu, L., McNichol, A. P., and Gustafsson, O.: Evaluation of gas chromatographic isotope fractionation and process contamination by carbon in compoundspecific radiocarbon analysis, Anal. Chem., 79(5), 2042-2049, 2007 c. 